\title{
Rancang Bangun Sistem Identifikasi Nomor Kendaraan pada Gerbang Tol menggunakan Metode Pengolahan Citra
}

\author{
Ratna Suryawati Mulyaningsih ${ }^{1}$, Moh. Abdullah Anshori ${ }^{2}$, Martono Dwi Atmadja ${ }^{3}$ \\ 1,2,3 Program Studi Jaringan Telekomunikasi Digital, \\ Jurusan Teknik Elektro, Politeknik Negeri Malang, Indonesia \\ 11 ratnasantoso48@gmail.com@gmail.com, ${ }^{2}$ moh.abdullah@polinema.ac.id, ${ }^{3}$ martono.dwi@polinema.ac.id
}

\begin{abstract}
The toll ticket payment mechanism still uses e-toll cards by attaching e-toll cards to the reader at the toll gate. This has several drawbacks, including the driver having a difficulty sticking the cards. At present a device has emerged to access the toll road without attaching a card known as the OBU. However, this device has a pretty expensive price. Therefore, an access system in and out of toll roads is made without using a card. With this system, users only need to register license plates in a dabase and there are applications that will also be used for payment, and as a trip monitoring. By using ultrasonic sensors and image processing methods, vehicle license plates that will enter the toll road can be detected. The test results are known to distance of the camera to the number plate to read correctly as far as 2 - 3 meter and when the distance of the camera to the number plate as far as $4 \mathbf{m}$, shows the wrong reading of the license plate. Ultrasonic sensor testing showed no failure in ten attempts. Ultrasonic sensors are used to detect the presence of objects vehicles when vehicles enter or exit the toll road.
\end{abstract}

Keyword- application, database, e-toll, image, ultrasonic

Abstrak- Mekanisme pembayaran tiket tol masih menggunakan kartu e-toll dengan menempelkan kartu e-toll pada reader di gerbang tol. Kekurangannya yaitu pengemudi kesulitan untuk menempelkan kartu sehingga tidak sedikit pengemudi yang harus menggunakan bantuan tongkat. Saat ini sudah muncul perangkat untuk mengakses jalan tol tanpa menempelkan kartu yang dikenal dengan OBU (On Board Unit). OBU akan bekerja seperti repeater sehingga palang akan terbuka tanpa menempelkan kartu pada gerbang. Akan tetapi, perangkat ini memiliki harga cukup mahal, sehingga tidak semua orang ingin membeli perangkat ini. Oleh karena itu, dibuat sistem akses keluar masuk jalan tol tanpa menggunakan kartu. Dengan adanya sistem ini, pengguna hanya perlu mendaftarkan plat nomor pada sebuah database dan terdapat aplikasi yang juga akan digunakan untk pembayaran, dan juga sebagai monitoring perjalanan. Dengan menggunakan sensor ultrasonik dan metode pengolahan citra, plat nomor kendaraan yang akan masuk tol dapat terdeteksi. Hasil pengujian diketahui bahwa jarak jangkauan kamera dengan plat nomor untuk terbaca dengan tepat sejauh 2 hingga 3meter dan disaat jarak jangkauan kamera dengan plat nomor sejauh 4 meter, menunjukkan pembacaan plat nomor yang salah. Pengujian sensor ultrasonik menunjukkan tidak ada kegagalan dalam 10 percobaan. Sensor Ultrasonik digunakan sebagai deteksi keberadaan (kendaraan) disaat kendaraan masuk atau keluar dari tol.

Kata kunci- aplikasi, citra, database, e-tol, ultrasonik

\section{PENDAHULUAN}

Jalan tol menjadi kebutuhan yang sangat penting bagi pengguna terutama di kota-kota besar. Pada saat ini, mekanisme pembayaran tiket tol masih menggunakan kartu etoll dengan cara menempelkan kartu e-toll pada reader yang ada di gerbang tol [1]. Kartu inilah yang kemudian dijadikan sebagai bukti perjalanan pengguna. Jumlah yang harus dibayar oleh pengguna pun dihitung berdasarkan kartu ini[2]. Selain itu, penyedia jasa tol juga menyediakan kartu berlangganan bagi pengguna yang sering menggunakan tol[3].
Hal ini memiliki beberapa kekurangan, di antaranya yaitu pengemudi sedikit kesulitan untuk menempelkan kartu sehingga tidak sedikit pengemudi yang harus menggunakan bantuan tongkat[4]. Saat ini sudah muncul sutau perangkat untuk mengakses jalan tol tanpa menempelkan kartu yang dikenal dengan OBU (On Board Unit)[5]. Pengguna dapat memasang OBU pada depan kendaraan dan memasukkan kartu e-toll ke dalamya, dan kemudian OBU akan bekerja seperti repeater sehingga palang akan terbuka tanpa menempelkan kartu pada gerbang[6]. Akan tetapi, perangkat ini memiliki 
harga cukup mahal, sehingga tidak semua orang ingin membeli perangkat ini.

Oleh karena itu, dibuat sistem akses keluar masuk jalan tol tanpa menggunakan kartu. Dengan adanya sistem ini, pengguna hanya perlu mendaftarkan plat nomor pada sebuah database dan terdapat aplikasi yang juga akan digunakan untk pembayaran, dan juga sebagai monitoring perjalanan[7][8]. Dengan menggunakan sensor ultrasonik dan metode pengolahan citra, plat nomor kendaraan yang akan masuk tol dapat terdeteksi[9][11]. Apabila saldo tidak mencukupi, maka saldo akan terhitung minus, dan dapat dibayarkan ketika transaksi selanjutnya. Apabila tidak segera dibayarkan, maka akan dikenakan denda yang nominalnya akan terus bertambah sesuai kebijakan pihak pelaksana. Dengan demikian, pengguna tol tidak perlu melakukan pengisian ulang di gerbang keluar, sehingga kemacetan akibat pengisian saldo di gerbang keluar dapat diminimalisir

Pada penelitian ini diusulkan suatu sistem pengkonversian plat nomor kendaraan yang masuk dan keluar pada tol kedalam bentuk teks dengan sensor image secara otomastis menggunakan tesseract OCR yang nantinya akan disamakan dengan plat nomor yang terdaftar dalam database. Kemudian terdapat aplikasi sebagai alat pembayaran dan monitoring riwayat perjalanan pada gerbang tol yang dilalui

\section{METODE}

Penelitian yang dilakukan termasuk dalam jenis penelitian dan pengembangan yang bertujuan untuk merancang sebuah sistem untuk mendeteksi kendaraan pada gerbang tol menggunakan kamera dan raspberry pi.

\section{A. Tahapan Penelitian}

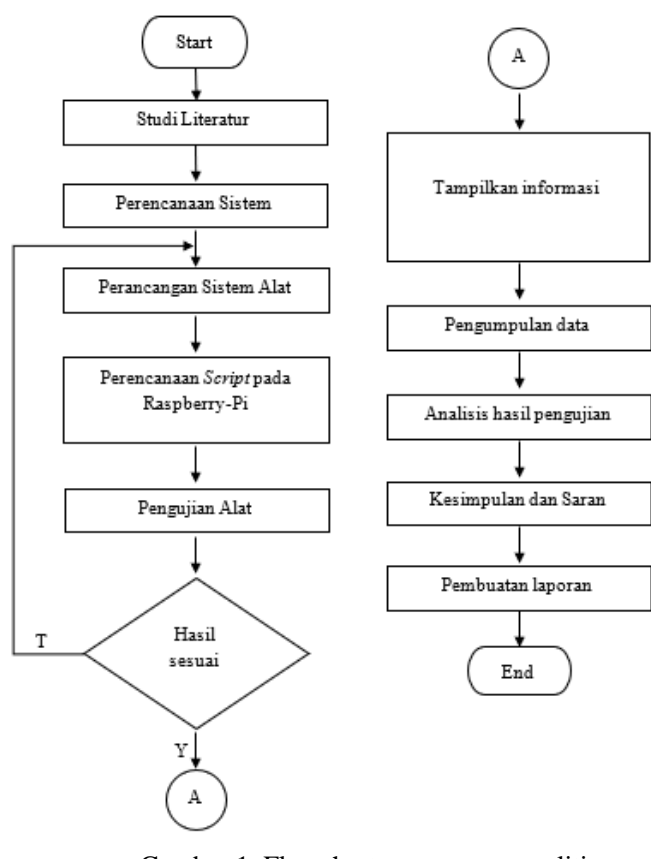

Gambar 1. Flowchart rancangan penelitian

\section{B. Blok Diagram Metode SSV}

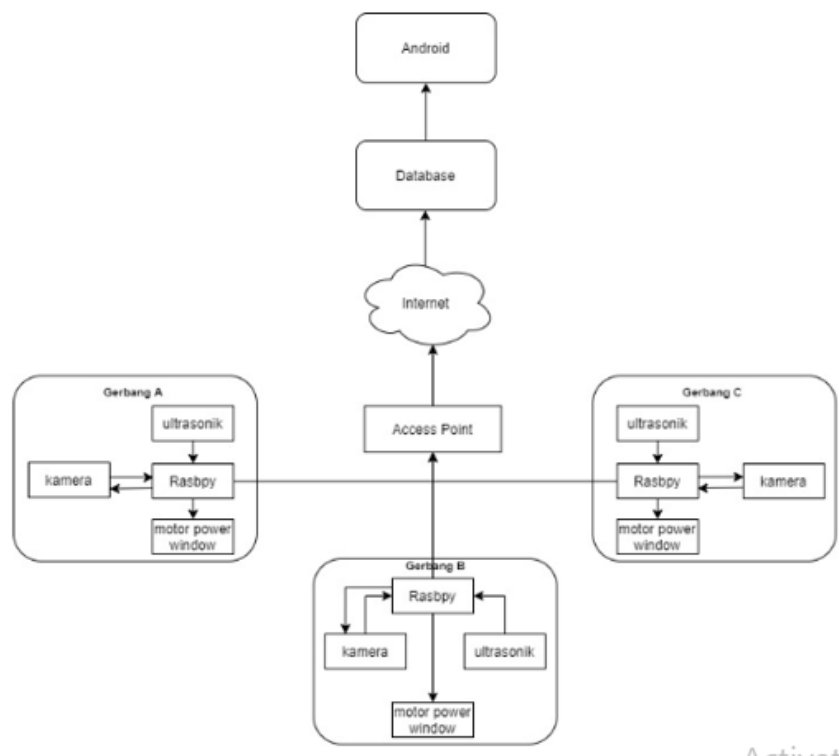

Gambar 2. Blok diagram sistem keseluruhan

Gambar 2 menjelaskan bahwa perangkat pendeteksian terdiri dari Sensor Ultrasonik, Raspberry Pi, Kamera, alarm, Database, dan aplikasi smartphone. Setiap bagian tersebut memiliki perannya masing-masing. Keterangan untuk tiap bagian adalah sebagaimana berikut:

1) Sensor Ultrasonik : Sensor ultrasonik berperan sebagai pendeteksi adanya kendaraan di gerbang tol, yang apabila terdeteksi adanya kendaraan, nantinya akan mengaktifkan mengaktifkan kamera

2) Mini PC :Mini pc yang digunakan adalah Raspberry Pi. Rasbpy digunakan sebagai control utama sistem tol ini. Dimana Raspberry melakukan penglolahan data terhadap masukan yang diterima dari setiap komponen yang dibutuhkan.

3) PC Camera USB 2.0 : PC camera USB 2.0 berperan sebagai sebagai media untuk mengcapture atau memfoto object plat nomor kendaraan sehingga didapat sebuah citra digital yang dapat diproses untuk merubah citra digital tersebut menjadi bentuk teks.

4) Motor Power Window: Motor Power Window digunakan untuk membuka palang ketika data telah dinyatakan cocok dengan database

5) Database : Database yang digunakan adalah Firebase, dipilih untuk penyimpanan utama data yang telah didapat dan diolah oleh mikrokontroller.

6) Smartphone: Smartphone berperan sebagai interface dan penampil informasi user. 
Jurnal Jaringan Telekomunikasi (Jurnal Jartel), E-ISSN: 2654-6531, P-ISSN: 2407-0807 Vol. 11, No. 1 (2021) 27-31

C. $\quad$ Flowchart Sistem Konversi Gambar ke Text

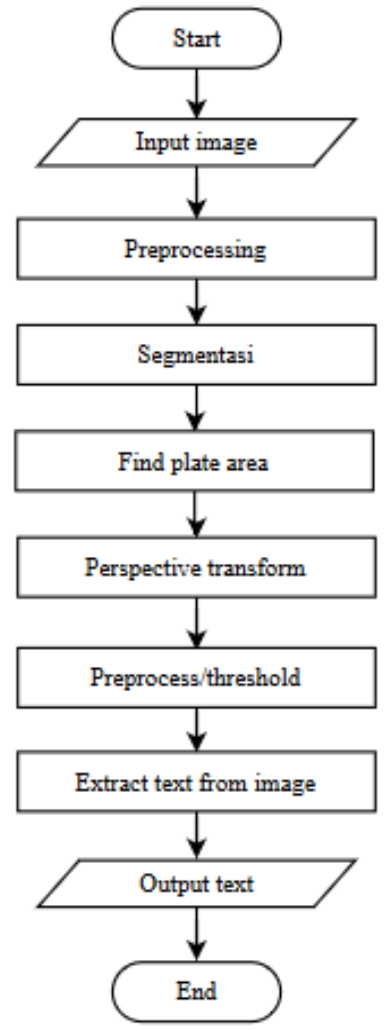

Gambar 3. Diagram alir perancangan sistem konversi gambar ke teks

D. Flowchart Database

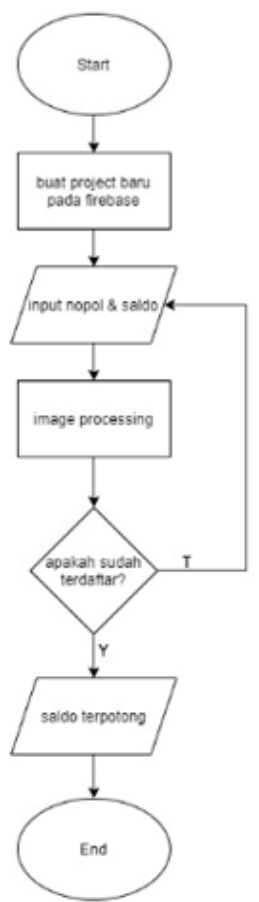

Gambar 4. Flowchart Database
E. $\quad$ Flowchart Keseluruhan Sistem

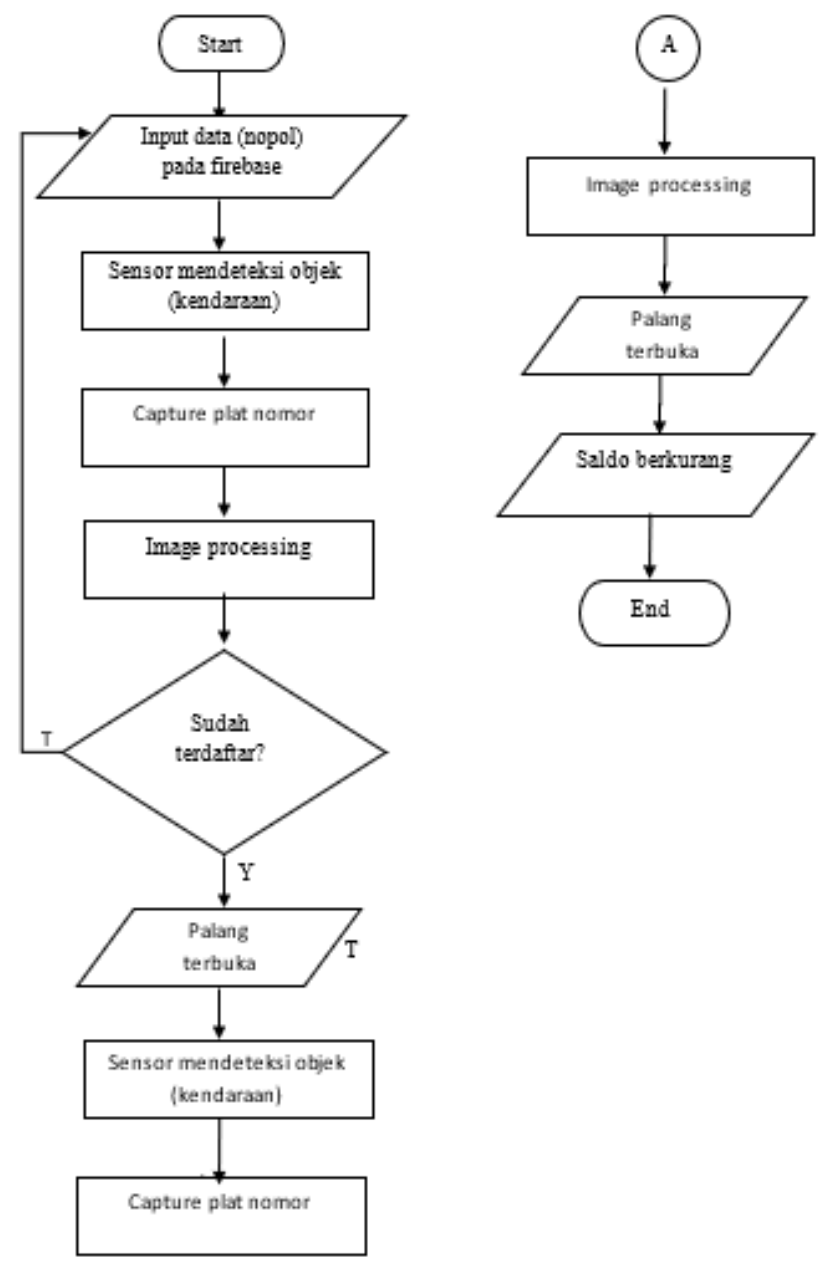

Gambar 5. Flowchart keseluruhan sistem

\section{HASIL DAN PEMBAHASAN}

\section{A. Hasil Implementasi Hardware}

Hasil implementasi hardware akan menjelaskan mengenai tampilan hardware yang akan digunakan sebagai sistem pendeteksi plat nomor kendaraan menggunakan raspberry pi dan kamera. Dalam sistem ini terdapat 3 gerbang, berikut tampilan salah satu gate yang digunakan ditunjukkan pada Gambar 6.
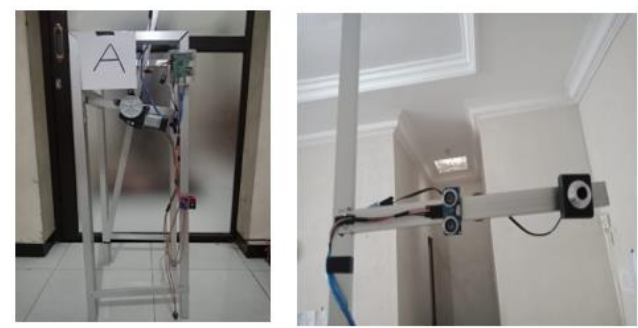

Gambar 6. Tampilan keseluruhan hardware 


\section{B. Hasil Implementaasi Software}

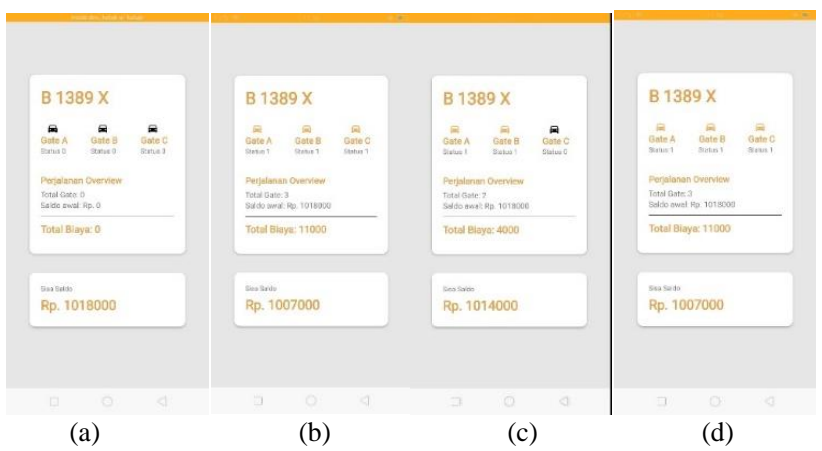

Gambar 7 (a) tampilan desain awal aplikasi (b) tampilan saldo terpotong 1 (c) tampilan saldo terpotong 2 (d) tampilan saldo terpotong 3

Gambar 7 menunjukkan gambar tampilan aplikasi android dimana pada gambar (a) menunjukkan tampilan desain awal aplikasi, gambar (b) menunjukkan tampilan saldo terpotong dari gate A ke gate B dengan tarif 4 ribu, gambar (c) menunjukkan tampilan saldo terpotong dari gate $\mathrm{A}$ ke gate $\mathrm{B}$ dan gate $\mathrm{C}$ dengan tarif 11 ribu, dan gambar (d) menunjukkan tampilan saldo terpotong dari gate $\mathrm{A}$ ke gate $\mathrm{C}$ dengan tarif 7 ribu.

\section{Implementasi Sistem Konversi Gambar ke Teks}

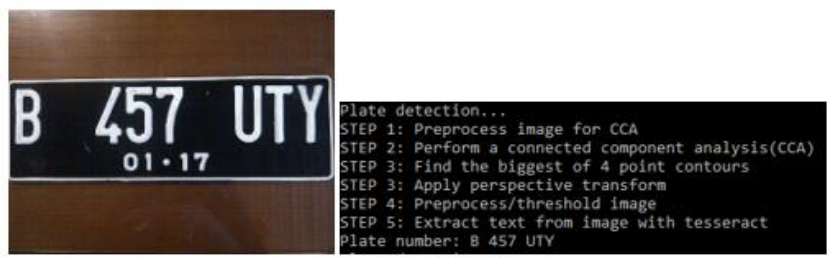

Gambar 8. Hasil implementasi sistem konversi gambar ke teks

\section{Pengujian Sensor}

Pengujian sensor dilakukan untuk mengetahui bahwa sensor yang digunakan pada penelitian ini dapat bekerja dengan baik atau tidak, ditunjukkan Tabel 1.

TABEL I

HASIL PENGUJIAN SENSOR ULTRASONIK

\begin{tabular}{cc} 
Percobaan & HASIL PENGUJIAN SENSOR ULTRASONIK \\
\hline ke- & Hasil Deteksi Sensor Ultrasonik \\
\hline 1 & Terdeteksi \\
2 & Terdeteksi \\
3 & Terdeteksi \\
4 & Terdeteksi \\
5 & Terdeteksi \\
6 & Terdeteksi \\
7 & Terdeteksi \\
8 & Terdeteksi \\
9 & Terdeteksi \\
10 & Terdeteksi \\
\hline
\end{tabular}

Pada tabel I menunjukkan bahwa setelah dilakukan pengujian sebanyak 10 kali percobaan tidak terjadi kegagalan deteksi keberadaan objek.

\section{E. Pengujian Ketepatan Konversi Gambar Plat Nomor ke Teks}

Pengujian ketepatan konversi gambar plat nomor ke teks bertujuan untuk mengetahui apakah sistem yang telah dibuat mampu mengubah gambar menjadi teks dengan tepat atau tidak. Pengujian dilakukan dengan cara membandingkan gambar plat nomor yang diperoleh dari hasil pengambilan gambar oleh kamera dengan hasil teks konversi gambar. Hasil pengujian ketepatan konversi gambar plat nomor ditunjukkan pada Tabel II.

Coverage jangkauan kamera merupakan cakupan yang dapat dijangkau oleh kamera berdasarkan jarak objek, sehingga gambar dideteksi dengan tepat. Berikut merupakan tabel coverage kamera usb 2.0

TABEL II

PENGUJIAN JANGKAUAN SUDUT KAMERA

\begin{tabular}{ccc} 
& \multicolumn{2}{c}{ PENGUJIAN JANGKAUAN SUDUT KAMERA } \\
\hline Jarak & Hambar & Hasil \\
\hline 1 meter & No contour found! & No detection!
\end{tabular}

2 meter

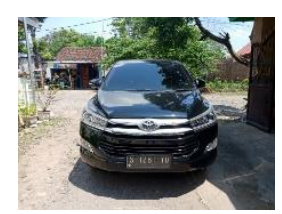

Plate number: $51261 \mathrm{YU}$

3 meter

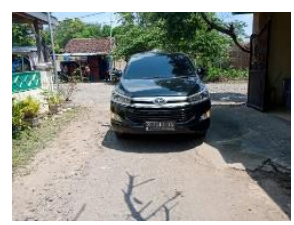

Plate number: $51261 \mathrm{YU}$

4 meter

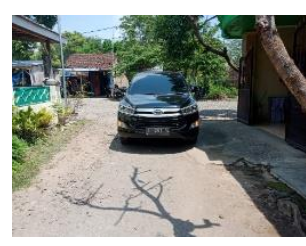

No contour found!

detection!

Dari hasil pengujian di atas, terlihat bahwa pada jarak 1 meter dengan tinggi palang 1,35m, kamera tidak dapat menjangkau plat nomor, sedangkan pada jarak $2 \mathrm{~m}$ dan $3 \mathrm{~m}$, gambar dapar dikonversi dengan baik. Dan pada jarak 4 meter sistem tidak dapat mengkonversi gambar karena objek terlalu jauh. 


\section{F. Pengujian Jangkauan Kamera pada Malam Hari}

Pengujian jangkauan kamera tehadap akurasi konversi gambar bertujuan untuk mengetahui sampai pada jarak berapa kamera dapat mengambil gambar yag dapat di konversi dengan benar dan tepa. Berikut adalah hasil pengujian jangkauan kamera terhadap akurasi konversi gambar ditampilkan pada table III

TABEL III

PENGUJIAN JANGKAUAN KAMERA PADA MALAM HARI

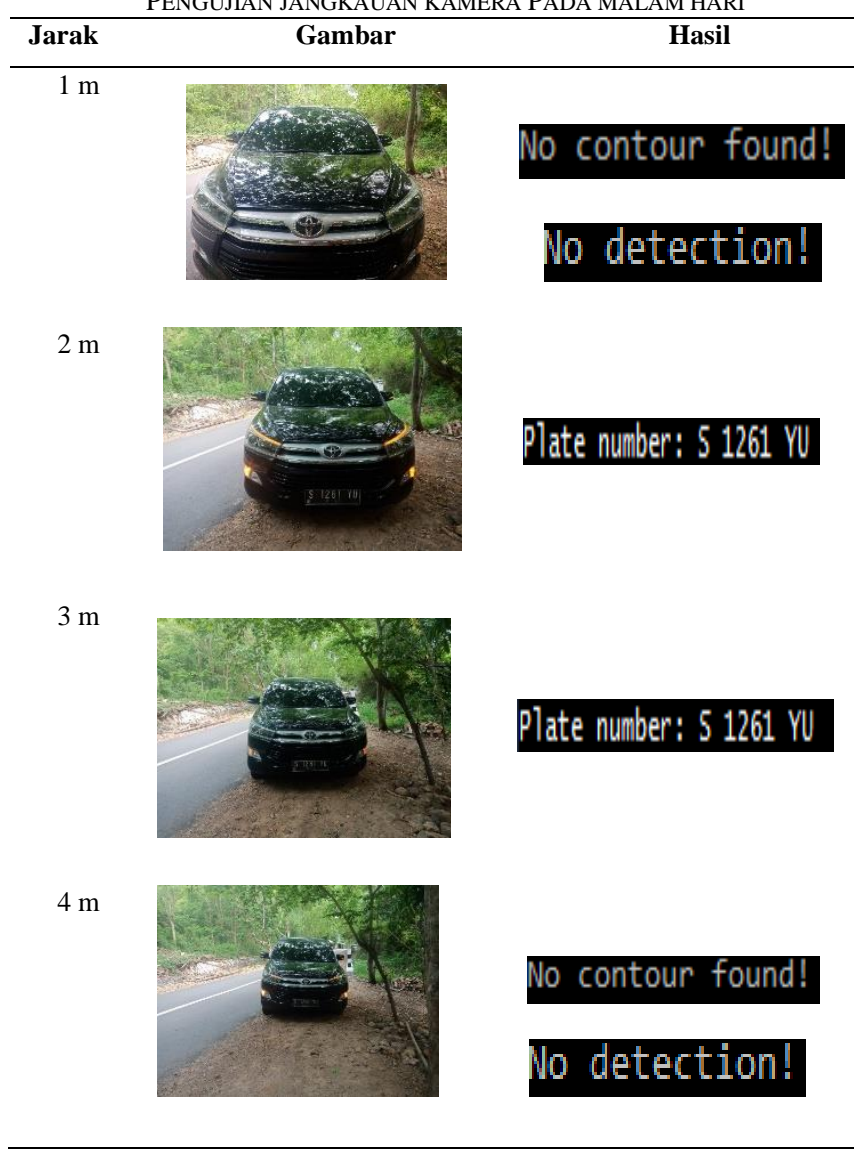

Dari hasil pengujian di atas, terlihat bahwa pada jarak 1 meter dengan tinggi palang $1,35 \mathrm{~m}$, kamera tidak dapat menjangkau plat nomor, sedangkan pada jarak $2 \mathrm{~m}$ dan $3 \mathrm{~m}$, gambar dapar dikonversi dengan baik. Dan pada jarak 4 meter sistem tidak dapat mengkonversi gambar karena objek terlalu jauh, ditunjukkan pada Tabel III.

\section{KESIMPULAN}

Jarak objek terhadap kamera paling dekat adalah 2 meter dikarenakan jangkauan kamera, dan paling jauh adalah 4 meter dikarenakan kemampuan lensa. Syarat pencahayaan pada gerbang tol yang mampu ditangkap oleh kamera adalah 1100 lux yang didapat dari hasil pengamatan. Sistem aplikasi android yang dibuat sesuai dengan yang direncanakan yaitu dapat memunculkan riwayat perjalanan atau gerbang tol yang dilalui pengguna, serta memunculkan tarif dan sisa saldo pengguna.

\section{REFERENSI}

[1] G. Udayana and I. Darmawiguna, "Pengembangan Prototipe Portal Otomatis Dengan Pendeteksian Plat Nomor Kendaraan Berbasis Raspberry Pi," Karmapati, vol. 5, no. 2, 2016.

[2] D. A. Irawati, "Pengembangan aplikasi pengenalan plat nomor kendaraan roda dua pada area parkir," Semin. Nas. Sains dan Teknol. 2015, no. November, pp. 1-11, 2015.

[3] S. Aulia and P. Maria, "Aplikasi Pendeteksi Plat Nomor Kendaraan Berbasis Raspberry Pi Menggunakan Website Untuk Pelanggaran Lalu Lintas," vol. 11, pp. 84-89, 2019.

[4] C. Raspberry, P. I. Dalam, and P. Sistem, "Implementasi Mikrokontroler Arduino Uno Dan Mini- Gerbang Tol Cerdas," vol. 8, no. 1, pp. 101-109, 2019.

[5] N. D. W. I. Cahyo, "Pengenalan Nomor Plat Kendaraan Dengan Metode Optical Character Recognition," vol. 2, pp. 75-84, 2019.

[6] Noprizal and Feri Candra, "Aplikasi Pengenalan Plat Nomor Kendaraan Di Universitas Riau," J. Fasilkom, vol. 9, no. 3, pp. 47-52, 2019.

[7] R. Akbar, M. Silvana, and A. F. Alizar, "Perancangan Aplikasi Pembayaran Non Tunai untuk Pengelolaan Bisnis Pencucian Mobil dengan Memanfaatkan Teknologi QR Code (Studi Kasus : Oto Pro Car Wash \& Detailling Padang )," p. 3, 2019.

[8] A. Hardiyanto, P. Studi, J. Telekomunikasi, J. T. Elektro, and P. N. Malang, "Sistem Manajemen Ticketing Pada Penyelenggara Pertandingan Liga Sepakbola Berbasis Near Field Communication ( Nfc ) Yang," pp. 22-29, 2017.

[9] L. A. Sandy, R. J. Akbar, and R. R. Hariadi, "Rancang Bangun Aplikasi Chat pada Platform Android dengan Media Input Berupa Canvas dan Shareable Canvas untuk Bekerja dalam Satu Canvas Secara Online," J. Tek. ITS, vol. 6, no. 2, 2017.

[10] C. Patel, A. Patel, and D. Patel, "Optical Character Recognition by Open source OCR Tool Tesseract: A Case Study," Int. J. Comput. Appl., vol. 55, no. 10, pp. 50-56, 2012.

[11] A. D. Kemal Anshari Elmizan, David Alfa Sunarna, Benni Bangun, "Optical Character Recognition (Ocr) Menggunakan Tesseract Dan Penerapannya Pada Industri Digital Di Indonesia," 2018. . 